\title{
Developed pressure data may provide misinformation when used alone to evaluate systolic function in isovolumetric left ventricle preparations
}

N. Murad and P.J.F. Tucci
Departamento de Fisiologia, Escola Paulista de Medicina, Universidade Federal de São Paulo, São Paulo, SP, Brasil

\section{Correspondence \\ P.J.F. Tucci \\ Disciplina de Fisiologia \\ Cardiovascular \\ Departamento de Fisiologia \\ EPM, UNIFESP \\ Rua Itacolomi, 280/121 \\ 01239-020 São Paulo, SP \\ Brasil \\ Fax: + 55-11-573-7820 \\ E-mail: ptucci@ fisiocardio.epm.br \\ Research supported by CNPq (No. 300.692/80-3) to P.J.F. Tucci. Publication supported by FAPESP.}

Received September 24, 1998 Accepted March 1, 1999

\section{Abstract}

We report data showing that developed pressure $\left(\mathrm{DP}_{\max }\right)$ may lead to opposite conclusion with respect to maximal developed circumferential wall stress $\left(\sigma_{\max }\right)$ when used to assess contractile function in left ventricle isovolumic preparations. Isovolumetric left ventricle preparations of rats with cardiac hypertrophy $(\mathrm{H} ; \mathrm{N}=10)$ induced by isoproterenol administration showed higher $\mathrm{DP}_{\max }(174 \pm 14 \mathrm{mmHg})$ than control $(\mathrm{C} ; \mathrm{N}=8)$ animals $(155 \pm 12 \mathrm{mmHg})$ or rats with regression ( $\mathrm{R} ; \mathrm{N}=8)$ of hypertrophy $(144 \pm 11 \mathrm{mmHg})$. In contrast, the estimated $\sigma_{\max }$ for $C\left(145 \pm 26 \mathrm{kdynes} / \mathrm{cm}^{2}\right)$ and $\mathrm{R}(133 \pm 17 \mathrm{kdynes} /$ $\left.\mathrm{cm}^{2}\right)$ was higher than for $\mathrm{H}\left(110 \pm 13 \mathrm{kdynes} / \mathrm{cm}^{2}\right)$. According to Laplace's law, the opposite results of $\mathrm{DP}_{\max }$ and $\sigma_{\max }$ may depend on the increased mass/volume left ventricle ratio of the hypertrophied hearts, which favored pressure generation. These results clearly show that $\mathrm{DP}_{\max }$ should be used with caution to analyze systolic function.

Muscle contractile capacity can be measured by determining maximal force developed during contraction. Maximal intraventricular developed pressure $\left(\mathrm{DP}_{\max }\right)$ is frequently utilized in isovolumetric left ventricle preparations as an index of myocardial contraction function, assuming that it correctly reflects maximal developed wall force (maximal developed wall stress $-\sigma_{\max }$ ) during contraction (1-3). This assumption is based on the fact that ventricular internal radius $\left(\mathrm{R}_{\mathrm{i}}\right)$ and wall thickness $(\mathrm{h})$ - the variables involved in the ventricular pressure and wall stress interact according to Laplace's

\section{Key words}

- Contractile function

- Developed pressure

- Wall stress

- Cardiac hypertrophy

- Laplace's law law - do not vary during isovolumetric contraction. This seems to be an acceptable postulate when the changes in ventricular function are evaluated in the same heart and $R_{i}$ and $h$ do not vary. However, comparison of $\mathrm{DP}_{\max }$ of different hearts with different $\mathrm{R}_{\mathrm{i}}$ and $h$ values is frequently utilized to evaluate myocardial contractile function (1-3), an oversimplification that can distort the interpretation of the results.

We have analyzed $\mathrm{DP}_{\max }$ and $\sigma_{\max }$ in isovolumetric left ventricle preparations from control rats $(\mathrm{C} ; \mathrm{N}=8)$, rats submitted to cardiac hypertrophy $(\mathrm{H} ; \mathrm{N}=10)$ by the ad- 
Table 1 - Structure and function parameters of rats with cardiac hypertrophy $(\mathrm{H})$, rats with regression of hypertrophy (R) and control rats (C).

LVW/BW: Left ventricular weight/body weight ratio; $\mathrm{m} / \mathrm{N}_{0}$ : mass (left ventricular weight)/volume (left ventricular chamber volume at zero diastolic pressure) ratio; $D_{\text {max: }}$ maximal value of developed pressure; $\sigma_{\max }$ : maximal wall circumferential stress; $* \mathrm{P}<0.05$ compared to control; ${ }^{+} \mathrm{P}<0.05$ compared to hypertrophied hearts. LVW/BW and $m / N_{0}$ were analyzed by ANOVA followed by the Kruskal-Wallis test. $\mathrm{DP}_{\max }$ and $\sigma_{\max }$ were analyzed by ANOVA followed by the Scheffé test.

\begin{tabular}{lcccc}
\hline & $\mathrm{LWW} / \mathrm{BW}(\mathrm{mg} / \mathrm{g})$ & $\mathrm{m} / \mathrm{N}_{0}(\mathrm{mg} / \mathrm{\mu l})$ & $\mathrm{DP}_{\max }(\mathrm{mmHg})$ & $\sigma_{\max }\left(\mathrm{kdynes} / \mathrm{cm}^{2}\right)$ \\
\hline $\mathrm{C}(\mathrm{N}=8)$ & $2.12 \pm 0.11$ & $4.23 \pm 0.82$ & $155 \pm 12$ & $145 \pm 26$ \\
$\mathrm{H}(\mathrm{N}=10)$ & $2.93 \pm 0.31^{*}$ & $6.15 \pm 1.43^{*}$ & $174 \pm 14^{*}$ & $110 \pm 13^{*}$ \\
$\mathrm{R}(\mathrm{N}=8)$ & $2.22 \pm 0.13^{+}$ & $3.9 \pm 0.56^{+}$ & $144 \pm 11^{+}$ & $133 \pm 17^{+}$
\end{tabular}

ministration of isoproterenol (ISO - $0.3 \mathrm{mg}$ $\mathrm{kg}^{-1}$ day $^{-1}$ during 8 days) and animals in which the regression $(\mathrm{R} ; \mathrm{N}=8)$ of cardiac hypertrophy was allowed to occur by interruption of drug treatment for 22 days. The results obtained for $\mathrm{DP}_{\max }$ and $\sigma_{\max }$ led to opposite conclusions, emphasizing the need to pay attention to the proper variable to be analyzed when using isovolumetric left ventricle preparations to evaluate myocardial contractile function.

The ascending aorta of 26 rats was cannulated after medial thoracotomy, and the hearts were perfused using the Langendorff technique in a retrograde manner, with KrebsHenseleit solution $(120 \mathrm{mM} \mathrm{NaCl}, 5.4 \mathrm{mM}$ $\mathrm{KCl}, 1.25 \mathrm{mM} \mathrm{CaCl}_{2}, 2.5 \mathrm{MgSO}_{4}, 2.0 \mathrm{mM}$ $\mathrm{NaHPO}_{4}, 27 \mathrm{mM} \mathrm{NaHCO}_{3}$ and $11 \mathrm{mM}$ glucose) at $37^{\circ} \mathrm{C}$ at a constant perfusion pressure of $100 \mathrm{mmHg}$. The perfusate was bubbled with a gas mixture of $95 \% \mathrm{O}_{2}: 5 \%$ $\mathrm{CO}_{2}$. Subsequently, the hearts were removed quickly, the left ventricular cavity was vented by apical puncture and a small fluid-filled latex balloon was placed into the left ventricular chamber via the left atrium. The balloon was connected to a pressure transducer by a short length of polyethylene tubing for the determination of left ventricular pressure. The right atrium, including the sinus node region, was removed and right ventricular pacing was performed using a stimulator delivering 5-ms, 5-mV monophasic square wave pulses. A stimulation rate of 180 beats/ min was used in all experiments. The liquid volume inside the left ventricular balloon was adjusted in such a way that diastolic pressure was zero. After an equilibration period of approximately $30 \mathrm{~min}$, a baseline pressure/volume ratio was determined for every heart; left ventricular peak systolic and end diastolic pressure were measured after $0.01-\mathrm{ml}$ increases of balloon volume until an end diastolic pressure of approximately $40 \mathrm{mmHg}$ was achieved.

This protocol allows us to define the plateau of maximal developed systolic circumferential stress in all cases, which is estimated from ventricular pressure measurements, ventricular volume, and weight, as described by Bing et al. (4). A spherical model was assumed, in which the left ventricular cavity is of radius $R_{i}$, and the chamber volume $\left(V_{c}\right)$ is considered to be the sum of the liquid volume inside the balloon plus the latex volume of the balloon [latex weight/ latex specific density (0.936)]. Thus, $\mathrm{V}_{\mathrm{c}}=4 /$ $3 \pi \mathrm{R}_{\mathrm{i}}{ }^{3}$ and $\mathrm{R}_{\mathrm{i}}=\left[\mathrm{V}_{\mathrm{c}} /(4 / 3 \pi)\right]^{1 / 3}$. The total heart volume (contained in a sphere of radius $R_{i}+$ $h$ ) is equal to the sum of $V_{c}$ and $V_{\text {wall }}$, where $\mathrm{V}_{\text {wall }}$ is the volume of the left ventricular wall $\left(\mathrm{V}_{\text {wall }}=\right.$ left ventricular weight $/ 1.05$, the specific gravity of myocardium). Hence, $\mathrm{V}_{\mathrm{c}}+$ $\mathrm{V}_{\text {wall }}=4 / 3 \pi\left(\mathrm{R}_{\mathrm{i}}+\mathrm{h}\right)^{3}$, and $\mathrm{R}_{\mathrm{i}}+\mathrm{h}=\left[\mathrm{V}_{\mathrm{c}}+\right.$ $\left.\left.\mathrm{V}_{\text {wall }}\right] /(4 / 3 \pi)\right]^{1 / 3}$. Left ventricular mid-wall circumferential stress is then derived from the equation proposed by Mirsky (5): $\sigma=$ $\left(\mathrm{PR}_{\mathrm{i}}^{2} / \mathrm{h}\right) /\left(2 \mathrm{R}_{\mathrm{i}}+\mathrm{h}\right)$, where $\mathrm{P}$ is pressure, $\mathrm{R}_{\mathrm{i}}$ is chamber radius and $h$ is wall thickness.

At the end of the experiment, the left atrium and right ventricular free wall were removed and the myocardial mass was weighed and used as the left ventricular weight (LVW). The data are presented in Table 1 . Data were analyzed statistically by one-way ANOVA complemented by the Scheffé or Kruskal-Wallis test. The left ventricular myocardial mass/body weight ratio (LVW/BW) increased after ISO and returned to normal levels with the regression of hypertrophy (C: $2.12 \pm 0.11 \mathrm{mg} / \mathrm{g} ; \mathrm{H}: 2.93 \pm$ 
$0.31 \mathrm{mg} / \mathrm{g}$; R: $2.22 \pm 0.13 \mathrm{mg} / \mathrm{g})$. Cardiac enlargement occurred with an increase of the mass/volume ratio $(\mathrm{C}: 4.23 \pm 0.82 \mathrm{mg} / \mu \mathrm{l}$; H: $6.15 \pm 1.43 \mathrm{mg} / \mu \mathrm{l}$ ) which characterized a concentric hypertrophy. Regression of cardiac enlargement was obtained with normalization of this ratio (R: $3.9 \pm 0.56 \mathrm{mg} / \mu \mathrm{l})$. An increase in maximal developed pressure $(\mathrm{C}$ : $155 \pm 12$ mmHg; H: $174 \pm 14$ mmHg; R: 144 $\pm 11 \mathrm{mmHg}$ ) occurred in the hypertrophied hearts despite a reduction of maximal developed wall stress (C: $145 \pm 26 \mathrm{kdynes} / \mathrm{cm}^{2} ; \mathrm{H}$ : $110 \pm 13$ kdynes $/ \mathrm{cm}^{2}$; R: $133 \pm 17$ kdynes/ $\left.\mathrm{cm}^{2}\right)$.

These results clearly show that, even though cardiac force generation by the hypertrophied myocardium was diminished, developed intraventricular pressure reached higher values than those observed in controls and in preparations with hypertrophy regression. It seems clear that the $\mathrm{DP}_{\text {max }}$ values may induce the misinterpretation that the contractile state of the concentrically hypertrophied hearts was enhanced. Indeed, this was the conclusion of other authors who utilized developed pressure as the sole indicator of contractile capacity in the same model of cardiac hypertrophy (1-3). Nevertheless, other studies (6-9) that evaluated force in muscle strips or in the isovolumetric left ventricle showed that stress generation is impaired in this model, indicating that the contractile state is depressed. According to Laplace's law, it is conceivable that $\mathrm{DP}_{\text {max }}$ should be higher in hypertrophied left ventricles, in spite of the impairment of the contractile state. According to the simpler expression of this law, wall stress and intraventricular pressure are related by the equation $\sigma=\mathrm{P} \mathrm{R}_{\mathrm{i}} / 2 \mathrm{~h}$. The rearrangement of this

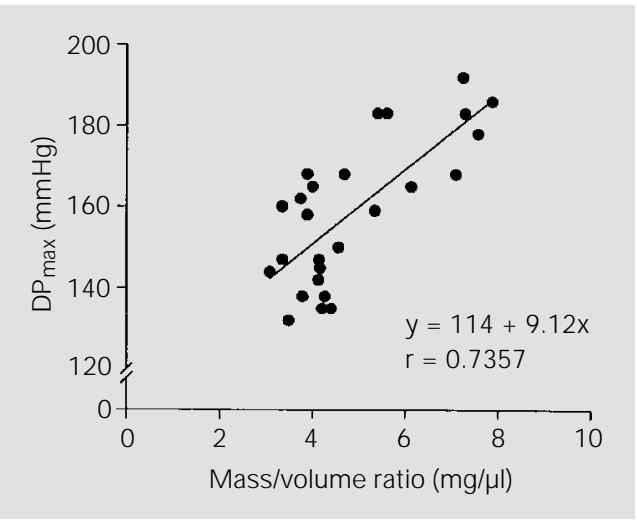

Figure 1 - Maximal developed pressure $\left(\mathrm{DP}_{\max }\right)$ correlated $(P<0.0001)$ with myocardial mass/chamber volume ratio, showing that ventricular pressure generation is enhanced as the mass/volume ratio increases. equation shows us that $P=2 \sigma h / R_{i}$, meaning that, for the same wall force, intraventricular pressure will be directly dependent on the $\mathrm{h} /$ $R_{i}$ ratio. Since $h$ depends on myocardial mass and $R_{i}$ on chamber volume, we may state that $\mathrm{DP}_{\text {max }}$ directly depends on the mass/ volume ratio, i.e., pressure generation is facilitated as the mass/volume ratio increases. Indeed, our data showed a very close correlation $(\mathrm{P}<0.0001)$ between the mass/volume ratio and the developed pressure (Figure 1).

On the other hand, the increased $\mathrm{DP}_{\max }$ of the hypertrophied myocardium indicates the improvement of the pumping function in cardiac concentric hypertrophy. Since concentric hypertrophy facilitates pressure generation, pumping ability is enhanced because pressure is the variable which regulates blood flow and therefore ventricular ejection. In conclusion, the present data clearly show that, during evaluation of systolic function in isovolumetric left ventricle preparations of hearts with concentric hypertrophy, the use of developed pressure as the sole indicator of contractile capacity needs to be carefully examined as a possible source of misleading information.

\section{References}

1. Taylor PB \& White DM (1983). Isoproterenol-induced changes in myocardial nucleic acids. Research Communications in Chemical Pathology and Pharmacology, 40: 511-514.
2. Taylor PB \& Tang Q (1984). Development of isoproterenol-induced cardiac hypertrophy. Canadian J ournal of Physiology and Pharmacology, 62: 384-389.

3. Tang Q, Taylor PB \& Helbing RK (1987).
Catecholamine induced cardiac hypertrophy. Canadian J ournal of Cardiology, 3 : 311-316.

4. Bing OHL, Brooks WW, Robinson KG, Slawsky MT, Hayes J A, Litwin SE, Sen S 
\& Conrad CH (1995). The spontaneously hypertensive rat as a model of the transition from compensated left ventricular hypertrophy to failure. J ournal of M olecular and Cellular Cardiology, 27: 283-290.

5. Mirsky I (1979). Elastic properties of the myocardium. A quantitative approach with physiological and clinical applications. In: Berne RM, Sperelakis N \& Gerger SR (Editors), Handbook of Physiology. The Heart. Vol. 1. Williams and Wilkins, Baltimore, MD, 479-531.

6. Tse J, Brackett ML \& Kuo J F (1978). Alter- ations in activities of cyclic nucleotide systems and in ß-adrenergic receptor-mediated activation of cyclic AMP-dependent protein kinase during progression and regression of isoproterenol-induced cardiac hypertrophy. Biochimica et Biophysica Acta, 542: 399-411.

7. Hayes J C, Wyss VL, Schenck RS \& Cohen $M L$ (1986). Effects of prolonged isoproterenol infusion on cardiac and vascular responses to adrenoceptor agonists. J ournal of Pharmacology and Experimental Therapeutics, 237: 757-763.
8. Stein B, Bartel S, Kirchhefer H, Kokott S, Krause EC, Neuman J, Schmitz W \& Scholz H (1996). Relation between contractile function and regulatory cardiac proteins in hypertrophied hearts. American J oumal of Physiology, 270: H2021$\mathrm{H} 2028$.

9. Vassalo DV, Vasquez EC \& Cabral AM (1988). Contractile performance of papillary muscles of renovascular hypertensive and isoproterenol-pretreated rats. Pharmacological Research Communications, 20: 61-72. 